\title{
Glycaemic status is an important risk factor for the occurrence of diabetic retinopathy in newly diagnosed type 2 diabetic patients
}

\author{
Sanjeev Kumar1*, Ajay Panwar², Pramod Kumar³, V. Atam4, Neetu Verma ${ }^{5}$, Pradeep Kumar ${ }^{6}$, Shilpa Bairwa \\ ${ }^{1}$ Senior Resident, Department of Medicine, K GM U, Lucknow, ${ }^{2}$ Senior Resident, Department of Neurology, K GM U, Lucknow, ${ }^{3}$ Associate \\ Professor, Department of Ophthalmology K GM U, Lucknow, ${ }^{4}$ Professor, Department of Medicine, K G M U, Lucknow, ${ }^{5}$ MBBS Student, GSVM \\ Medical College Kanpur, UP, ${ }^{6}$ Professor, Department of Physiology, K GM U, Lucknow, ${ }^{7}$ Senior Resident, Department of Pathology SMS \\ Medical College Jaipur
}

\section{A B S T R A C T}

Objective: To assess the frequency of diabetic retinopathy (DR) and correlation with HbA1c in newly diagnosed type 2 diabetic patients. Materials and Methods: The study was conducted at a tertiary care medical centre in north India. All patients of $>30$ to $<60$ years of age, who were newly (within a month) diagnosed type 2 diabetes mellitus, according to World Health Organization (WHO) criteria and American Diabetes Association (ADA) recommendations, were included in the study. $\mathrm{HbA} 1 \mathrm{c}$ was estimated from venous blood collected in ethylene diamine tetra acetic acid (EDTA) test tube, using boronate affinity chromatography (HPLC). Diabetic retinopathy was assessed by fundus examination using direct ophthalmoscope after dilatation of pupils. Early treatment diabetic retinopathy study (ETDRS) scale was used to assess the severity of diabetic retinopathy. Results: Twenty-eight percent of the newly diagnosed cases were found to have diabetic retinopathy, of which $73.52 \%$ were of mild NPDR (non-proliferative diabetic retinopathy) and $26.47 \%$ were of moderate NPDR. Mean FPG of population with retinopathy was $194.05 \pm 29.82 \mathrm{mg} / \mathrm{dl}$ and that of population without retinopathy was $175.67 \pm 27.71 \mathrm{mg} / \mathrm{dl}$. Mean $\mathrm{HbA} 1 \mathrm{c}$ of population with retinopathy was $7.71 \pm 1.01 \%$ and that of population without retinopathy was $7.22 \pm 0.74$. Conclusions: Mild NPDR is the most common form of diabetic retinopathy in newly diagnosed type 2 DM patients. Study demonstrated a very significant positive correlation between level of glycosylated hemoglobin $(\mathrm{HbA} 1 \mathrm{c})$ and frequency of diabetic retinopathy in these cases. So, glycaemic status is an important risk factor for the occurrence of diabetic retinopathy.

Key words: HbA1c Diabetes Retinopathy

\section{INTRODUCTION}

Diabetic retinopathy (DR) is the most frequent cause of blindness among adult age 20 to 75 years. ${ }^{1,2}$ It is an important health problem worldwide. Chennai Urban Rural Epidemiology (CURES) Eye Study reported the prevalence of DR to be $17.6 \%$ in India, which is less in comparison to the western world. ${ }^{3}$ However, globally, due to a large population of diabetes patients, it has been estimated that about $30 \%$ of people with DM have DR. ${ }^{4}$ It is not surprising that glycemic index
(GI), which is a physiological measure for classifying carbohydrate-containing foods according to postprandial glycemic potential, has been related to many disorders, such as diabetes and cardiovascular disease and diabetic retinopathy ${ }^{5,6}$ and hence a risk factor. Many pathophysiological effects follow postprandial hyperglycemia after eating a high-GI meal may leads to diabetes or diabetic complications including DR. ${ }^{7}$

Several studies reported that the reduction of $\mathrm{HbA1c}$ to $7 \%$ can cause a decrease in the prevalence of DR as well as 
in the rate of progression..$^{8-10}$ The purpose of the present study was to study the prevalence of diabetic retinopathy in newly diagnosed type $2 \mathrm{DM}$ patients and it's correlation with $\mathrm{HbA1}$ c levels, in a tertiary medical care centre in north India, thus to see, whether the results obtained in other studies replicate here or the epidemiological factors play a role and bring out results, different from other studies.

\section{MATERIALS AND METHODS}

The present study was a cross-sectional study conducted at KG Medical University Lucknow, All patients with type 2 diabetes mellitus who attended Medicine OPD and Endocrinology OPD, were included in the study who fulfilled the following inclusion criteria: age $<30$ to $>60$ years, written informed consent and diagnosed as type $2 \mathrm{DM}$ within last 1 month, at the time of enrollment. Cases were defined according to the following WHO diagnostic criteria and ADA recommendations. ${ }^{11}$

- $\quad F P G \geq 126 \mathrm{mg} / \mathrm{dl}(7.0 \mathrm{mmol} / \mathrm{l})$. (Fasting defined as no caloric intake for at least $8 \mathrm{~h}$.), or

- 2-h plasma glucose $\geq 200 \mathrm{mg} / \mathrm{dl}$ (11.1 mmol/l) during an OGTT. The test was performed as described by the World Health Organization, using a glucose load containing the equivalent of $75 \mathrm{~g}$ anhydrous glucose dissolved in water, or

- In a patient with classic symptoms of hyperglycemia or hyperglycaemic crisis, a random plasma glucose $\geq 200 \mathrm{mg} / \mathrm{dl}(11.1 \mathrm{mmol} / \mathrm{l})$, or $\mathrm{A} 1 \mathrm{C} \geq 6.5 \%$.

Patient of known hypertension with or without treatment, ischemic heart disease, cardiomyopathy, valvular heart disease, heart failure, chronic pulmonary illness, severe anaemia, hemoglobinopathies and those who were already on antidiabetic medications were excluded from the study. Diabetic retinopathy was assessed by doing fundus examination by using direct ophthalmoscope after pupillary dilatation. Venous blood was collected after 8 hours fasting into a test tube coated with Ethylene Diamine Tetra Acetic Acid (EDTA) for HbA1c. HbA1c was estimated by using Nycocard immunoassay kit (USA). Fasting and postprandial plasma glucose was measured using chem-7 auto analyzer (Erba Mannheim) of transasia bio-medicals Ltd.

Severity of diabetic retinopathy was classified using early treatment diabetic retinopathy study (EDRTS) scale. Data were analyzed for mean, percentage, standard deviation, Student ' $t$ ' test, Fisher's exact test, by using SPSS 16(Statistical Package for the Social Sciences) for Windows (SPSS, Chicago, IL). The ' $\mathrm{t}$ '-test and Fisher's exact tests were applied to study quantitative and qualitative data, respectively with ' $\mathrm{p}$ ' value $<0.05$ was considered statistically significant.

\section{RESULTS}

A total of 121 patients of newly diagnosed type 2 diabetes mellitus were selected for this cross sectional study. Out of which $79(65 \%)$ were males and $42(35 \%)$ females. Mean age of the population was $51.08 \pm 5.30$ years. Mean age of male population was $51.70 \pm 5.83$ years and that of female population was $49.41 \pm 6.90$ years. The incidence of diabetic retinopathy in population and sex-wise distribution is shown in table 1.

Out of 100 patients of newly diagnosed type 2 DM; $29 \%$ patients were found to have diabetic retinopathy. Out of this $28 \%$ cases, 25 cases $(75.86 \%)$ were of mild NPDR and 09 cases $(24.14 \%)$ were of moderate NPDR. No patients of severe NPDR and PDR were detected. 34 cases of DR had 22 males and 12 females. However, when male and female populations were compared for incidence of retinopathy applying Fisher's exact test, no significant difference was found $(\mathrm{p}>1.0000)$ regarding the incidence of diabetic retinopathy between the two populations. The incidence of DR, when compared with fasting plasma glucose (FPG) and HbA1c (\%), yielded the results depicted in table 2 .

Mean FPG of population with retinopathy was $206.69 \pm$ $25.20 \mathrm{mg} / \mathrm{dl}$ and that of population without retinopathy was $170.18 \pm 26.80 \mathrm{mg} / \mathrm{dl}$. This shows that FPG is positively associated with the incidence of diabetic retinopathy and correlation was found extremely significant $(\mathrm{p}<0.0001)$. Mean HbA1c of population with

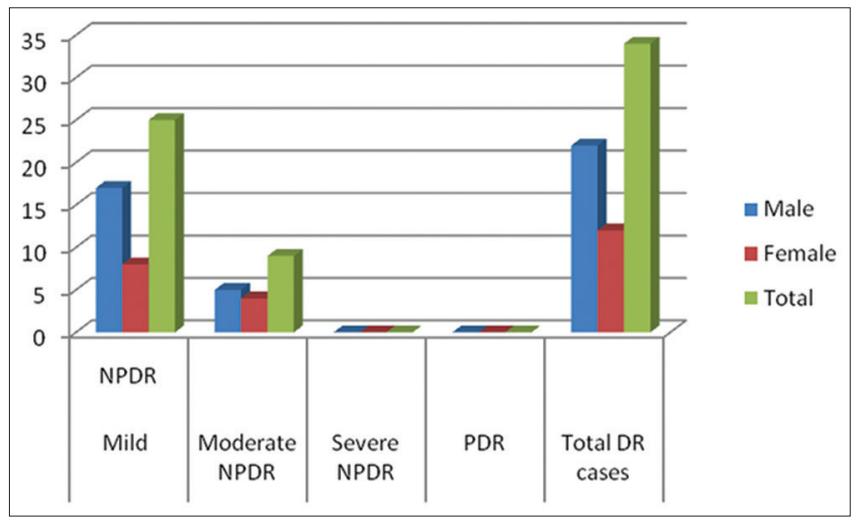

Figure 1: Comparison of Incidence of diabetic retinopathy in population and gender wise distribution

\begin{tabular}{|c|c|c|c|c|c|}
\hline & $\begin{array}{l}\text { Mild } \\
\text { NPDR }\end{array}$ & $\begin{array}{l}\text { Moderate } \\
\text { NPDR }\end{array}$ & $\begin{array}{l}\text { Severe } \\
\text { NPDR }\end{array}$ & PDR & $\begin{array}{c}\text { Total DR } \\
\text { cases }\end{array}$ \\
\hline Male & 17 & 05 & 0 & 0 & 22 \\
\hline Female & 08 & 04 & 0 & 0 & 12 \\
\hline Total & 25 & 09 & 0 & 0 & 34 \\
\hline
\end{tabular}




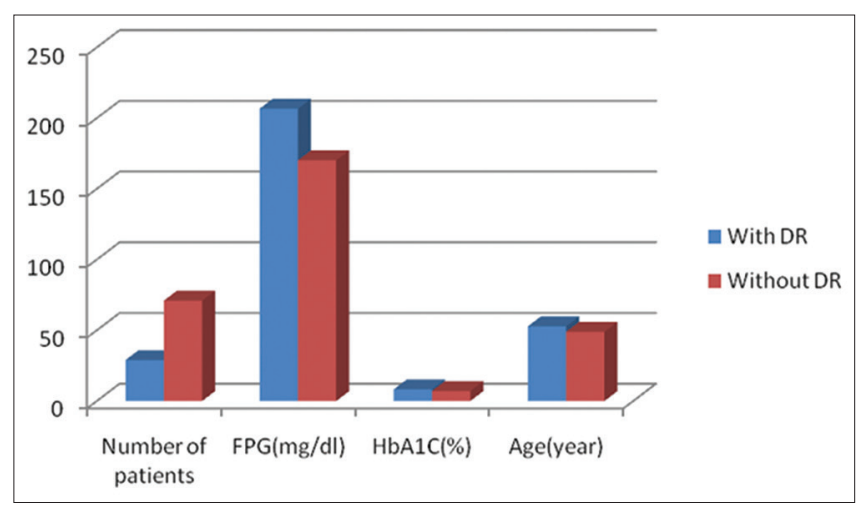

Figure 2: Comparative parameters of the patients with Ddiabetic Retinopathy

\begin{tabular}{|c|c|c|c|}
\hline Parameters & With DR & Without DR & $P$ value \\
\hline Number of patients & 34 & 87 & - \\
\hline $\begin{array}{l}\text { Fasting plasma } \\
\text { glucose }(\mathrm{mg} / \mathrm{dl})\end{array}$ & $194.05 \pm 29.82$ & $175.67 \pm 27.71$ & 0.0020 \\
\hline $\mathrm{HbA} 1 \mathrm{c}(\%)$ & $7.71 \pm 1.01$ & $7.22 \pm 0.74$ & 0.0157 \\
\hline Age ( year) & $54.57 \pm 6.49$ & $46.48 \pm 7.15$ & 0.0012 \\
\hline
\end{tabular}

retinopathy was $8.23+0.85 \%$ and that of population without retinopathy was $7.08+0.44 \%$. Thus, HbA1c is positively associated with the incidence of diabetic retinopathy and correlation was found extremely significant $(\mathrm{p}<0.0001)$.

Mean age of population with retinopathy was $52.82+5.27 \mathrm{yrs}$ and that of population without retinopathy was $48.95+6.27 \mathrm{yrs}$. So, age is positively associated with the incidence of diabetic retinopathy in population and correlation was found very significant $(\mathrm{p}<0.0043)$.

\section{DISCUSSION}

Diabetic retinopathy remains a major complication of type 2 diabetes and requires early detection for best treatment. ${ }^{12}$ The prevalence of any diabetic retinopathy among people with newly diagnosed type- 2 diabetes was $28 \%$, which is less than the prevalence of diabetic retinopathy, 35-39\%, With best of my knowledge this is the only study to screen diabetic retinopathy at tertiary health care in north India in newly diagnosed diabetes mellitus. Our findings are in line with reports from recent population studies in which the prevalence of diabetic retinopathy ranged from $6 \%$ to $23 \% .14,15$ The lowest estimates $\left(6.2 \%\right.$ in Australia ${ }^{16}$ and $10.2 \%$ in the USA $^{17}$ come from studies that undertook simultaneous diabetes diagnosis and retinal screening. These differences in prevalence of retinopathy in newly diagnosed type 2 diabetics might be due to variable time interval between onset and detection of the disease. It can be a result of socio-economical factors which mainly determine the access to and availability of medical care and variation in defining the presence of diabetes mellitus. Our data showed that newly diagnosed type 2 diabetics with retinopathy had higher HbA1c and higher fasting plasma glucose levels. USA has now started diagnosing diabetes based on the presence of an elevated HbA1c. ${ }^{18}$ Some study claimed that requirement for fasting or glucose challenge), may be replaced by $\mathrm{HbA1c}{ }^{19}$

\section{CONCLUSION}

On the basis of our data we concluded that there was statistically significant positive correlation between level of glycosylated hemoglobin (HbA1c) and frequency of diabetic retinopathy in the newly diagnosed cases of type 2 diabetes mellitus and Mild NPDR is most common form of diabetic retinopathy in all retinopathy subjects.

\section{REFERENCES}

1. Raman R, Rani PK, Reddi Rachepalle S, Gnanamoorthy P, Uthra S, Kumaramanickavel G, et al. Prevalence of diabetic retinopathy in India: Sankara Nethralaya Diabetic Retinopathy Epidemiology and Molecular Genetics Study report 2. Ophthalmology 2009, 116:311-318.

2. Cheung N, Mitchell $P$ and Wong TY. Diabetic retinopathy. Lancet 2010; 376:124-136.

3. Rema M, Deepa R and Mohan V. Prevalence of retinopathy at diagnosis among type 2 diabetic patients attending a diabetic centre in South India. Br J Ophthalmol 2000; 84:1058-1060.

4. Yau JW, Rogers SL, Kawasaki R, Lamoureux EL, Kowalski JW and Bek T, Meta-Analysis for Eye Disease. META-EYE Study Group. Global prevalence and major risk factors of diabetic retinopathy: Diabetes Care 2012; 35:556-564

5. Kaushik S, Wang JJ, Flood V, Tan JS, Barclay AW, Wong TY, et al. Dietary glycemic index and the risk of age-related macular degeneration. Am J Clin Nutr 2008; 88: 1104-1110.

6. Chiu CJ, Klein R, Milton RC, Gensler G and Taylor A. Does eating particular diets alter risk of age-related macular degeneration in users of the Age-Related Eye Disease Study supplements? Br J Ophthalmol 2009a; 93:1241-1246.

7. Riccardi G, Rivellese AA and Giacco R. Role of glycemic index and glycemic load in the healthy state, in prediabetes, and in diabetes. Am J Clin Nutr 2008; 87:269S-274S.

8. Pradeepa R, Surendar J, Indulekha K, Chella S, Anjana RM and Mohan V. Association of serum adiponectin with diabetic microvascular complications among south Indian type 2 diabetic subjects. Clin Biochem 2015; 48(1-2):33-38.

9. Ghazanfari Z, Haghdoost AA, Alizadeh SM, Atapour J and Zolala F. A comparison of $\mathrm{HbA} 1 \mathrm{C}$ and fasting blood sugar tests in general population. Int J Prev Med 2010;1:187-194.

10. Hsu C, Chen $Y$ and Sheu WH. Glycemic variability and diabetes retinopathy: A missing link. J Diabetes Complications 2014; Dec:3.

11. Rabasseda $X$. Drugs Today (Barc). A report from the $74^{\text {th }}$ American Diabetes Association Scientific Sessions (May 13-17 - San Francisco, California, USA). 2014;50(8):579-597. 
12. Ellis D, Burgess $\mathrm{PI}$ and Kayange P. Management of diabetic retinopathy. Malawi Med J 2013; 25(4):116-120.

13. Sosale A, Prasanna Kumar KM, Sadikot SM, Nigam A, Bajaj S, Zargar $\mathrm{AH}$, et al. Chronic complications in newly diagnosed patients with Type 2 diabetes mellitus in India. Indian J Endocrinol Metab 2014;18(3):355-360.

14. Kostev K, Jockwig A, Hallwachs A and Rathmann W. Prevalence and risk factors of neuropathy in newly diagnosed type 2 diabetes in primary care practices: a retrospective database analysis in Germany and U.K. Prim Care Diabetes 2014;8(3):250-255.

15. Ali A, Iqbal F, Taj A, Iqbal Z, Amin MJ and lqbal QZ. Prevalence of microvascular complications in newly diagnosed patients with type 2 diabetes. Pak J Med Sci 2013; 29(4):899-902.
16. Tapp RJ, Shaw JE, Harper CA, De Courten MP, Balkau B, Mc Carty DJ, et al. The prevalence of and factors associated with diabetic retinopathy in the Australian population. Diabetes Care 2003; 26:1731-1737.

17. Klein R, Klein BE, Moss SE and Linton KL. The Beaver Dam Eye Study. Retinopathy in adults with newly discovered and previously diagnosed diabetes mellitus. Ophthalmology1992; 99:58-62.

18. Association AD. Diagnosis and classification of diabetes mellitus. Diabetes Care 2010; 33(Suppl 1):S62-S69.

19. Cowie CC, Rust KF, Byrd-Holt DD, Gregg EW, Ford ES, Geiss LS, et al. Prevalence of Diabetes and High Risk for Diabetes Using A1C Criteria in the U.S. Population in 19882006. Diabetes Care. Mar 2010; 33(3): 562-568.

\section{Authors Contribution:}

SK - Contributed to the original idea, designed the study, enrolled the patients, collected the data and analysed, prepared the manuscript and reviewed the manuscript; AP - Conceived hypothesis, designed study, patient enrolment, data collection, data analysis, preparing of manuscript and reviewing the manuscript; PK-1 - Contributed to the study design, data analysis, preparing of manuscript and reviewing the manuscript; VA - Contributed to patient enrolment and data collection; NV and PK and SP-Contributed to data analysis, preparing of manuscript and reviewing the manuscript. 